AperTO - Archivio Istituzionale Open Access dell'Università di Torino

\title{
Validity and Reliability of the Interpersonal Competence Questionnaire: Empirical Evidence from an Italian Study
}

\section{This is the author's manuscript}

Original Citation:

Availability:

This version is available http://hdl.handle.net/2318/1524369

since 2015-09-09T09:03:42Z

Published version:

DOI:10.1007/s10862-015-9499-5

Terms of use:

Open Access

Anyone can freely access the full text of works made available as "Open Access". Works made available under a Creative Commons license can be used according to the terms and conditions of said license. Use of all other works requires consent of the right holder (author or publisher) if not exempted from copyright protection by the applicable law. 


\section{Journal of Psychopathology and Behavioral Assessment Validity and Reliability of the Interpersonal Competence Questionnaire: Empirical Evidence from an Italian Study --Manuscript Draft--}

\begin{tabular}{|c|c|}
\hline Manuscript Number: & JOBA-D-15-00032R1 \\
\hline Full Title: & $\begin{array}{l}\text { Validity and Reliability of the Interpersonal Competence Questionnaire: Empirical } \\
\text { Evidence from an Italian Study }\end{array}$ \\
\hline Article Type: & Original Research \\
\hline Keywords: & interpersonal competence; ICQ; validity; emotion regulation; Empathy \\
\hline Corresponding Author: & $\begin{array}{l}\text { Luciano Giromini } \\
\text { San Diego, UNITED STATES }\end{array}$ \\
\hline \multicolumn{2}{|c|}{$\begin{array}{l}\text { Corresponding Author Secondary } \\
\text { Information: }\end{array}$} \\
\hline \multicolumn{2}{|c|}{ Corresponding Author's Institution: } \\
\hline \multicolumn{2}{|c|}{$\begin{array}{l}\text { Corresponding Author's Secondary } \\
\text { Institution: }\end{array}$} \\
\hline First Author: & Luciano Giromini \\
\hline \multicolumn{2}{|c|}{ First Author Secondary Information: } \\
\hline \multirow[t]{7}{*}{ Order of Authors: } & Luciano Giromini \\
\hline & Gaia de Campora \\
\hline & Emanuela Brusadelli \\
\hline & Ester D'Onofrio \\
\hline & Alessandro Zennaro \\
\hline & Giulio Cesare Zavattini \\
\hline & Margherita Lang \\
\hline \multicolumn{2}{|c|}{ Order of Authors Secondary Information: } \\
\hline \multicolumn{2}{|l|}{ Funding Information: } \\
\hline Abstract: & $\begin{array}{l}\text { Interpersonal competence is crucial to human life, and poor social functioning is a } \\
\text { typical feature of various psychopathological conditions. Given the relevance of the } \\
\text { construct, increasing attention has recently been paid to the Interpersonal Competence } \\
\text { Questionnaire (ICQ; Buhrmester et al., 1988), a } 40 \text {-item self-report measuring five } \\
\text { domains of interpersonal competence. To provide additional data on the cross-cultural } \\
\text { adaptability of the ICQ, we developed an Italian version and investigated its } \\
\text { psychometric properties with two independent student samples. Respondents were } \\
\text { mostly women (about three quarters), ranging in age from } 18 \text { to } 57 \text {. Study } 1(n=408) \\
\text { tested factor structure, internal consistency, and convergent validity. Study } 2(n=59) \\
\text { investigated test-retest reliability. Taken together, the results of both these studies } \\
\text { provided support for the cross-cultural applicability of the ICQ, and revealed interesting } \\
\text { associations between interpersonal competence and constructs such as well-being, } \\
\text { emotion dysregulation and empathy. }\end{array}$ \\
\hline
\end{tabular}


Dear Dr. Iselin,

Thank you or the opportunity to revise and resubmit our manuscript "Validity and Reliability of the Interpersonal Competence Questionnaire: Empirical Evidence from an Italian Study" which had been JOBA-D-15-00032. We appreciate the input provided by you and the four reviewers and believe it has substantially enhanced the contribution our manuscript can make to the literature. Below we have copied your decision letter followed by the reviews and to each point made we provide a description of how we addressed the issue or a rationale for why we did not in the rare instance when that was applicable. Our comments to you and the reviewers are designated with "Reply:" at the start of the paragraph.

Thank you and best wishes on behalf of all co-authors,

(First Author)

Dear Dr. XXXX:

Thank you for your recent submission of the above referenced manuscript to the Journal of Psychopathology and Behavioral Assessment. The review process on your manuscript is now complete. I was fortunate to receive the input of four reviewers who have expertise in this area of research, and I have reviewed the manuscript in detail. There are a number of strengths in your manuscript. It is well-written and contributes to our knowledge on interpersonal competence, which is of interest to our readership. We also had concerns about your manuscript which are outlined below. As you know, acceptance of a manuscript for publication in the Journal of Psychopathology and Behavioral Assessment requires a favorable evaluation from all reviewers. Based upon the reviews, I regret that I cannot currently accept the manuscript for publication. I would, however, like to invite you to submit a revision that addresses our concerns. In that revision, please pay special attention to the following:

- Address questions about whether the ICQ is measuring a general interpersonal construct rather than specific interpersonal skills.

Reply: We have provided a stronger justification for the use of the ICQ as a measure of specific interpersonally skills, and we have included in the article the results of additional CFAs aimed at testing the models suggested by Reviewer 1 (please see below).

- Better explicate your hypotheses in the introduction.

Reply: We followed this advice, and the hypotheses are now better explicated in a new section titled "Aims and Hypotheses".

- Please use a Bonferroni adjustment for multiple comparisons, and only discuss correlations meeting that more conservative threshold.

Reply: Thank you for this recommendation, we have followed this advice.

Thank you for considering the Journal of Psychopathology and Behavioral Assessment as a publication outlet. I know that a considerable amount of time and effort went into the preparation of this manuscript. I trust that the reviews will be taken in the spirit in which they were intended, which is to improve science and help you strengthen this manuscript. If you choose to revise your manuscript, it will be due within 90 days and will undergo additional reviews (which may include feedback from new reviewers).

Best regards, Anne-Marie Iselin, Ph.D.

Associate Editor 
Reviewer 1's

Reviewer \#1: The article examines the psychometric properties of the Italian version of the ICQ. It is certainly a valuable addition to the field to publish and validate an Italian ICQ version. However, I have couple of mostly theoretical issues that, if addressed by the authors, would make the contribution of the article much stronger.

Major issues:

Theoretical positioning of interpersonal competence:

The authors state that Interpersonal Competence is defined as the ability to successfully interact with others (p. 1). This definition is very broad and seems to substantially overlap with other well-known constructs such as social skills, social intelligence, or emotional intelligence; and it seems to include more specific constructs like empathy, interpersonal sensitivity, etc.. It would be very useful to disentangle the role of interpersonal competence from these other constructs and to state what makes interpersonal competence unique. Does interpersonal competence (or, the five dimensions) predict something the other constructs do not predict? Why are the five ICQ dimensions "the chief dimensions" (p. 2, 1.36)? Are there others? These issues should be addressed in the introduction. In the discussion, the reader might be interested in some guidance as to when researchers should use the ICQ, and when similar measures like the Social Skills Inventory etc..

Reply: We appreciate this input and have added additional material to the Introduction and Discussion. More in detail, the second paragraph of the Introduction has been added to disentangle the role of interpersonal competence from other similar constructs; the third paragraph has been revised to more clearly state what makes the ICQ unique; and the last sentence of the fourth paragraph has been added to clarify why we talk about "chief dimensions". As for the Discussion, we have added a paragraph (toward the end, it begins with "As reviewed above, the construct of interpersonal competence [...]") to give some guidance as to when researchers may want to use the ICQ vs. other measures.

Factor structure:

I appreciate the fact that the authors replicate the five-factor structure proposed by previous authors. However, the results show that the correlations between the dimensions are substantial, which makes me wonder whether a unidimensional model or a hierarchical model with one super-factor would not show even better fit. Relatedly, I am wondering whether it would be justifiable to calculate a total ICQ score, or whether it is necessary to stick with the subscores.

Reply: This is a very interesting point. We have tested two additional models (see "Additional Analyses" at the end of the section titled "Factor Structure"), and our results overall suggest that the model suggested by Buhrmester et al. (1988) still provides a better fit. However, in the Discussion we now suggest that future research might further address this topic (see the last sentence of the second paragraph).

Hypotheses:

It seems that generally, most ICQ scales are related to the other personality measures in the same way (e.g., selfcontrol is positively related to all ICQ dimensions, nonacceptance is negatively related to all ICQ dimensions, etc.). Related to my previous question, does this not speak in favor of a general interpersonal competence construct rather than different skills? Nevertheless, in the introduction the authors highlight that one strength of the ICQ is that it measures "different degrees of interpersonal functioning in a variety of domains" (page 1), and they stick with the the five dimensions instead of a total score. In this case, I would expect the authors also to generate separate/differential predictions/hypotheses for each dimension with the other measures.

In the current version, the hypotheses are very broad and not very well derived. For example, in the case of the DERS, there is only one sentence: "Because being able to regulate the emotion is important to being able to establish good interpersonal relationships, we predicted that the Italian ICQ would correlate negatively with the DERS." More theoretical reasoning and previous empirical evidence (from emotion regulation research or research on emotional intelligence, for example) would be necessary to make that prediction, generally and for each ICQ dimension. For example, it could be that emotion regulation might be more relevant to conflict resolution and self-disclosure than to initiating relationships and asserting influence. I would urge the authors to better substantiate each hypothesis. This would fit better in a separate section in the introduction rather than in the method section. 
Reply: We have followed this advice and now the Introduction presents separate/differential predictions/hypotheses for each dimension of the ICQ (see the second paragraph of "Aims and Hypotheses").

Please describe previous findings on the reliability and validity of the ICQ in the introduction and not in the methods.

Reply: The text describing previous findings on the reliability and validity of the ICQ has been moved to the place you recommended (see last paragraph before "Aims and Hypotheses").

A substantial shortcoming of the study is, as the authors note only briefly, the exclusive focus on self-report measures (p.14, line 19). It would be useful to elaborate more on how convergent/predictive/criterion validity of the test could be established in future studies (e.g., performance-based tests, behavioral measures, ratings by others, etc.). In addition, it would be useful to generate some concrete predictions for the different ICQ domains regarding how they would relate to concrete external criteria.

Reply: Thank you; we now elaborate more on how future studies could further address the convergent validity of the ICQ (see the last paragraph of the paper).

Can the mean scores on the five dimensions be compared to means in other studies that used similar samples (students)? Are there cultural differences, i.e., do Italians score higher or lower on some dimensions than Americans?

Reply: We appreciate this input, and have added a comparison between our ICQ scores and those reported by Buhrmester et al. (1988) (see second paragraph of the Results section titled "ICQ Scores"). We also follow up on this point in the Discussion, suggesting that future research might further investigate potential crosscultural differences on the ICQ scores (see the last paragraph of the article).

Minor issues:

* Buhrmester is frequently misspelled in the article (Burhmester instead of Buhrmester).

Reply: Thanks for catching that. This has been fixed throughout the entire manuscript.

* The descriptions of the instruments used for assessing convergent validity are very lengthy and could be shortened in case there is a word limit; likewise for the description of the procedure and some of the references. From my point of view it would be more important and interesting to the reader to focus on the theoretical positioning of the interpersonal competence construct and the five dimensions, as well as on the justification of the hypotheses.

Reply: We appreciate this suggestion, and have extended the introduction in line with this and previous comments. Also, we have moved the predictions from the section titled "Measures" to the Introduction, which has contributed to shortening the section titled "Measures". We did not further shorten this section because Reviewer 4 actually asked to provide more information concerning the measures included in the study.

* On page 4, the authors make predictions for the Big Five, except for conscientiousness. Why? This should be explained.

Reply: The section this comment refers to has been largely revised, and the current version includes a prediction concerning consciousness (see the section on Emotional Support in the section "Aims and Hypotheses").

* $\quad$ Page 5, line 9: copying probably should mean coping

Reply: Thank you; this has been fixed. 
* Will the Italian version be made available to other researchers, e.g., as a supplementary material? If so, this should be mentioned in the article.

Reply: We have added a footnote saying that the reader may request a copy of the Italian ICQ via email (see the first paragraph of "Method").

* Table 4: PGWBI: Anxiety and depression could maybe be renamed into "absence of anxiety/ depression" or "low anxiety/ depression", because the positive effects are slightly confusing otherwise.

\section{Reply: Thank you; we have made this change accordingly.}

Reviewer \#2:

JOBA-D-15-00032

"Validity and reliability of the Interpersonal Competence Questionnaire: Empirical Evidence from an Italian Study"

This two-study manuscript describes the translation and validation of an Italian version of Buhrmester's (1988) Interpersonal Competence Questionnaire. The first study collected a large sample in order to assess the factor structure, internal consistency, and convergent validity of the translated ICQ. The second study utilized a smaller sample to test the one-month test-retest reliability. Student samples were utilized for both. Overall the Italian ICQ appears valid and reliable, and this is consistent with other translations of the ICQ (German, French, and Polish versions). This manuscript is concise, well-written, and clear. The methods are easy to follow. With regards to literature review, I particularly liked that the authors note Burhmester indicates that different interpersonal competencies are required for different situations and relationships, which is sometimes overlooked in manuscripts utilizing the ICQ. Overall I have one question regarding Methods, some minor suggestions for the Discussion, and a few minor wording suggestions that the authors can choose to use or not.

\section{Reply: Thank you very much for your appreciation of our work.}

With regards to the methods for Study 1 - the authors used a back translation approach in order to account for any inconsistencies between the English and Italian versions of the ICQ. Were any modifications necessary in order to complete the translation, or were the translations deemed adequate. And if they were deemed adequate, how was that determined?

\section{Reply: We appreciate this input, and have added a couple of sentences to clarify (see the first paragraph of the section titled "Method")}

With regards to Study 2, are 59 participants sufficient to assess test-retest reliability? If so, where did the authors get this appropriate number from, and is there a citation that can be added to support this choice?

Reply: We have added the requested information. Specifically we have added the following sentence "This sample size (i.e., $n=59$ ) is bigger than that used by Buhrmester et al. (1988) to evaluate the test-retest reliability of the $\operatorname{ICQ}(n=31)$ in their original article, and it is consistent with current recommendations (e.g., Hertzog, 2008; Walter, Eliasziw, \& Donner, 1998) and practice (e.g., Calamia, Markon, \& Tranel, 2013; Paiva et al., 2014) in psychology and medicine." (see "Recruitment Procedures and Participants", "Study 2").

I also have two points with regards to the reported limitations of the study:

1. The ICQ is a measure of self-reported interpersonal competence. This doesn't necessarily mean that ratings will map on to behavioral/observed interpersonal competence or ratings by others (e.g., informant reports). It is possible some of the unexpected correlations between the Italian ICQ and other measures could be due to this 
Reply: Good point. In line with this comment, we have slightly extended on the need to replicate our findings with other methods (see last paragraph, second point/limitation).

2. I agree that an entirely student sample is a limitation to this project and it should be noted. However, Buhrmester's original validation was with a student sample and many other studies have since used the ICQ with student-only samples. I think this caveat can lessen the impact of this limitation and should be noted.

Reply: Thanks for this suggestion; we have now included your consideration within the following sentence: "Even though Buhrmester et al. (1988) original study as well as many other ICQ validation studies also used student-only samples, future investigations encompassing community samples would certainly be beneficial." (last paragraph of the article).

A few minor wording changes:

- P. 2 I would remove "recently" - 1988 is not very recent

Reply: This section has been largely revised, and we have clarified what we meant by "recently" (i.e., we meant to refer to the recent Polish and German cross-validations).

- P. 2 line 39, there is an inconsistency in tense in this sentence

Reply: This has been fixed, thanks.

- P. 3 line 36 "three quarters" would sound better

Reply: We have made the suggested change.

- P. 4 Are these scale names the same as what Burhmester uses? I think it would be most appropriate to use the labels of Burhmester's original article

Reply: We have followed this advice, and we now use the labels of Buhrmester's original article.

- P. 8 line 31, I dislike the use of "obviously" - I think it would be sufficient to say that future validation is required, but note that this was not the purpose of this study

Reply: We have made the suggested modification.

- P 9 line 19 “again" - it isn’t clear what this is referring to

Reply: We have clarified, and removed the word "again".

- P. 12 the authors have repeated the opening sentence for the 3rd time (Abstract, Intro, Discussion) and the next sentence was in the introduction. It would be more interesting to the reader if you varied thsese sentences

Reply: In line with this comment, we have made some small changes to the Abstract, Intro and Discussion.

- P 13 citations in lines 21-24, it seems to me that the authors are extrapolating from the areas of study of these manuscripts, reporting their actual findings in a sentence for each would be more accurate.

Reply: We have followed this advice, and the current version states "This finding is well in line with previous studies indicating that interpersonal competence is central to human well-being and mental health, as it mediates the process of daily stress generation (Cummings et al., 2013) and associates with various personality disorder symptoms (Muralidharan et al., 2010)." (third paragraph of Discussion). 
Reviewer \#3: This manuscript outlines two studies conducted to introduce and validate an Italian version of the ICQ. The samples for the validation studies were student samples comprised mostly of women. the author(s) review the literature that examines the reliability and validity of the ICQ as well as Polish, French and German versions. From all accounts the instrument appears to be valid across cultures. I have a few critiques:

1. The manuscript needs to be edited for small grammatical errors, including plural vs singular references.

Reply: Thank you for catching that, we have now fixed a number of grammatical errors.

2. The author(s) need to explain why they chose the ICC rather than a pearson correlation for the test retest reliability. In one sentence they refer to the statistic as an inter-rater reliability which is accurate but doesn't apply in this context.

Reply: This is an interesting point. We are aware that many researchers have used Pearson correlation coefficients to investigate test-retest reliability (and in fact Buhrmester also presented correlation coefficients for this purpose). However, current recommendations indicate that using intraclass-correlation coefficients is a better method to investigate test-retest. Briefly, the main issue is that if at $\mathrm{T} 2$ the scores are always - let's say - 15 points higher than at T1, then the Pearson correlation would be 1.00 even though the scores at T1 and $\mathrm{T} 2$ would in fact be notably different from each other. We now include a reference to Walter and colleagues (i.e., Walter, D. S., Eliasziw, M., \& Donner, A. (1998). Sample size and optimal design for reliability studies. Statistics in Medicine, 17, 101-110).

3. Although the author(s) suggest that their sample is a limitation, I think more could be said about this.

Reply: We have further elaborated this section accordingly. The current version states "First, our sample was made up of students, with a majority of women, which somewhat limits the generalizability of the results. Even though Buhrmester et al. (1988) original study as well as many other ICQ validation studies also used student-only samples, future investigations encompassing community samples would certainly be beneficial. Moreover, additional research on cross-cultural differences on the mean ICQ scores also would be interesting, given that our Italian sample produced some different mean scores compared to Buhrmester et al.'s (1988) data."

4. I would also like to see more theoretical reasoning about why the ICQ would be related to the other scales used for construct validity.

Reply: We have followed this advice, and have largely revised the description of our hypotheses and predictions. Specifically, we have added a new section titled "Aims and Hypotheses" (at the end of the Introduction), which better explains the rationale for our predictions.

Reviewer \#4: The current manuscript attempted to examine the validity of the Interpersonal Competence Questionnaire in a sample in which such scale has not been previously validated.

The manuscript is well-written and it is easy to read. It addresses an important topic that is likely to be of interest to the readership of JOBA.

The manuscript needs minor revisions with regard to some issues.

Reply: We thank you very much for your appreciation of our work.

Abstract

I suggest to report something similar to last line reported on Page 2 ("this research is intended to provide useful information on the cross-cultural applicability of the ICQ") instead to just report that "no studies have utilized the ICQ in Italy" (Page 1). 
Reply: Thanks; we have followed this suggestion, and the current version states "To provide additional data on the cross-cultural adaptability of the ICQ, we developed an Italian version and investigated its psychometric properties with two independent student samples."

Introduction

I suggest that the authors clarify both in the Abstract and in the Introduction the age range of interest in their study.

Reply: We have followed this advice. The Abstract now states "Respondents were mostly women (about three quarters), ranging in age from 18 to 57". The Introduction now states "Two studies were conducted, and a total of 467 respondents (mostly women, ranging in age from 18 to 57), from three different Italian universities, contributed to this research." (see Aims and Hypotheses).

Please report results about ICQ factorial validity (e.g., whether confirmatory factor analyses have been examined; with which age-groups?) in previous studies.

Reply: We have made the suggested change, and the current version states "In Buhrmester et al.'s (1988) original studies, the internal consistency of the ICQ scales ranged from .77 to .87 (Cronbach's alpha), and a series of factor analyses confirmed the hypothesized, five-factor structure of the ICQ. Very similar results were found with adult samples (ranging in age 18 to 40) with a Polish (Górska, 2011) and a German (Kanning, 2006) versions too." (see Introduction, before Aims and Hypotheses).

Please report a sentence to introduce both studies before to move into Study 1.

Reply: We have followed this suggestion too (please see the last paragraph of Aims and Hypotheses).

Study 1

Please report explicitly (page 3 - line 2) that the study refers to college students.

Reply: This section has been slightly revised, and we believe the current version makes it very clear that our samples include college students.

Recruitment Procedures and Participants

Please report some information about response rate.

Reply: We have clarified that "All students in class decided to participate" (see Recruitment Procedures and Participants).

Measures and Predictions

Please report the number of items that have been considered in each of the considered subscales.

Reply: We have made the requested change.

The NEO Five-Factor Inventory - Alphas for agreeableness and extraversion were fairly low. Please report a comment about that. In addition, please report alphas for these subscales in some previous studies (with non Italian and with Italian samples).

Reply: We appreciate this input, and have further elaborated this section. The current version states "Though at a first sight some of these values may appear slightly lower than ideal, it should be noted that: (a) it is not uncommon for the NEO inventories to achieve Cronbach alphas lower than .70 (for a review, see McCrae, Kurtz, Yamagata, \& Terracciano, 2011); and (b) the idea that alpha values should necessary be higher than .70 has been heavily criticized by psychometricians and statisticians (e.g., John \& Soto, 2007; Sijtsma, 2009). In short, as McCrae et al. (2011) pointed out, "Internal consistency seems to have little to do with the validity of NEO Inventory facets" (p. 20)."

The Questionnaire of Cognitive and Affective Empathy - Please report some information to support that a five- 
factor solution is a reliable factorial solution with Italian data as well as in the original ones.

Reply: We have conducted a series of CFAs to test the factor structure of the Italian QCAE. The hierarchical model proposed by Reiners et al. (2011) fit fairly well our data: $\mathrm{RMSEA}=.066, \mathrm{CFI}=.92$, NNFI $=.91$.

Noteworthy, some of us are currently working on some other Italian data, which also concur to indicate that the Italian QCAE has a similar factor structure to that suggested by Reiners and colleagues. Providing detailed information on the cross-cultural applicability of the QCAE, however, goes beyond the purposes of the current article. Thus, we have simply summarized this information with the following statement " $A$ confirmatory factor analysis also confirmed that the factor structure proposed by Reniers et al. (2011) adequately fit the Italian data (a more detailed paper on the cross-cultural applicability of the QCAE is currently in preparation)."

Study 2

Recruitment Procedures and Participants

Please report some information about response rate.

Reply: We have clarified that "All students in class agreed to participate" (see Recruitment Procedures and Participants).

General Discussion

Please report some comments about the strong correlation between "Initiating Relationships" and "Asserting Influence" factors.

Reply: We very much appreciated this input. In the Discussion, the current version of the article has introduced a new paragraph, which states "The relatively strong correlation between Initiation and Negative Assertion ( $r=.62)$ also is noteworthy. In Buhrmester et al.' (1988) study these two domains correlated .47 , in Kanning's (2006) they correlated .43, and in Górska's (2011) .61. Thus, our findings are somewhat in line with previous research, and closely resemble those reported with the Polish ICQ. A possible explanation for this phenomenon is that individuals with good Initiation skills might be particularly prone to assert personal rights and express displeasure in that they are not too preoccupied to become or feel lonely. Put simply, because they know they will be able to initiate new relationships, they do not feel the need to please others in order to be accepted by them. This explanation would be supported by the fact that both Initiation and Negative Assertion positively correlated with extraversion, but did not correlate or correlated negatively with Agreeableness (Table 4). Another possible explanation is that individuals with good Initiation skills might have more opportunities to interact with others, and this would give them more chances to learn how to assert their personal rights. Indeed, as Buhrmester et al. (1988) pointed out, "people who are skilled in one context may have greater opportunity to become skilled in other contexts that arise from earlier success" (p. 998). Future research might further investigate these hypotheses too."

Minor issues

Page 2 - line 1. " growing interest has been devoted the Interpersonal Competence Questionnaire". Should It be " growing interest has been devoted to the Interpersonal Competence Questionnaire"?

Reply: This sentence has been largely revised. It now states "Given the relevance of the construct, and the lack of instruments specifically targeting these chief dimensions of interpersonal competence, it is not surprising that the ICQ has recently received increasing attention, and has been cross-validated into some non-U.S. cultures."

Page 4. I suggest to report "Measures and Hypotheses" instead of "Measures and Predictions".

Reply: Thank you; we have used the word "Hypotheses" rather than "Predictions", and moved that section to the Introduction. Thus, toward the end of the Introduction, the article now includes a section titled "Aims and Hypotheses". 
Validity and Reliability of the Italian ICQ

Validity and Reliability of the Interpersonal Competence Questionnaire:

Empirical Evidence from an Italian Study

Luciano Giromini ${ }^{1}$, Gaia de Campora ${ }^{2}$, Emanuela Brusadelli ${ }^{3}$, Ester D’Onofrio ${ }^{4}$, Alessandro Zennaro $^{1}$, Giulio Cesare Zavattini ${ }^{4}, \&$ Margherita Lang $^{3}$

${ }^{1}$ Department of Psychology, University of Turin, Italy

${ }^{2}$ Department of Psychology, University of Cagliari, Italy

${ }^{3}$ Department of Psychology, University of Milano-Bicocca, Italy

${ }^{4}$ Department of Dynamic and Clinical Psychology, Sapienza University of Rome, Italy

Corresponding Author:

Luciano Giromini, Ph.D., Department of Psychology, University of Turin, Italy

Tel. (+39) 011091 3060; Email: luciano.giromini@unito.it

Email address of all authors:

Luciano Giromini: luciano.giromini@unito.it

Gaia de Campora: gaiadecampora@gmail.com

Emanuela Brusadelli: emanuela.brusadelli@gmail.com

Ester D’Onofrio: esterdonofrio@libero.it

Alessandro Zennaro: alessandro.zennaro@unito.it

Giulio Cesare Zavattini: zavattini.giuliocesare@gmail.com

Margherita Lang: margherita.lang@unimib.it 
1

2

3

\begin{abstract}
Interpersonal competence is crucial to human life, and poor social functioning is a typical feature of various psychopathological conditions. Given the relevance of the construct, increasing attention has recently been paid to the Interpersonal Competence Questionnaire (ICQ; Buhrmester et al., 1988), a 40-item self-report measuring five domains of interpersonal competence. To provide additional data on the cross-cultural adaptability of the ICQ, we developed an Italian version and investigated its psychometric properties with two independent student samples. Respondents were mostly women (about three quarters), ranging in age from 18 to 57. Study $1(n=408)$ tested factor structure, internal consistency, and convergent validity. Study $2(n=59)$ investigated test-retest reliability. Taken together, the results of both these studies provided support for the cross-cultural applicability of the ICQ, and revealed interesting associations between interpersonal competence and constructs such as well-being, emotion dysregulation and empathy.
\end{abstract}

Keywords: interpersonal competence; ICQ; validity; emotion regulation; empathy. 
Validity and Reliability of the Interpersonal Competence Questionnaire:

Empirical Evidence from an Italian Study

Broadly defined as the ability to interact successfully with others, interpersonal competence plays a key role in various areas of human life. It is important, for example, to romantic relationships (e.g., Frisbie, Fitzpatrick, Feng, \& Crawford, 2000; Lamke, Sollie, Durbin \& Fitzpatrick, 1994), professional success (e.g., Riggio \& Taylor, 2000), parenting (e.g., BartleHaring \& Sabatelli, 1997), popularity and coping in high school and youth (Buhrmester, Furman, Wittenberg, \& Reis, 1988; Cairns, Cairns, \& Neckerman, 1989), and self-esteem (Buhrmester et al., 1988). Crucially, impaired interpersonal competence associates with vulnerability to stress and negative life events (Cummings et al., 2013; Segrin, 2001), loneliness (DiTommaso, Brannen-McNulty, Ross, \& Burgess, 2003), and, perhaps more importantly, psychopathology (Segrin, 1990, 1993; Skodol et al., 2005). Indeed, it is fairly well known that poor interpersonal functioning is a key feature of virtually all personality disorders (Kim, Pilkonis, \& Barkham, 1997; Muralidharan, Sheets, Madsen, Craighead, \& Craighead, 2010; Skodol et al., 2005).

Interpersonal competence builds on psychological abilities such as social skills and empathy, and it may be seen as a 'conceptual cousin' of social and emotional intelligence. The term social skills (Lieberman, 1982), indeed, refers to "the ability to give and obtain information, and to express and exchange attitudes, opinions, and feelings" (p. 63). As such, social skills subserve interpersonal functioning by promoting effective communication between people. The term empathy derives from the Greek word Empatheia, which means "appreciation of another person's feelings" (Astin, 1967; Wispe, 1986). Broadly defined, it refers to the ability, and/or willingness, to 'put oneself in another's shoes.' Due to its being fundamental to the 
understanding of other's emotions and feelings, empathy largely contributes to effective interpersonal interactions, too. While social skills and empathy are conceived of as relatively specific abilities contributing (along with other skills) to interpersonal competence, the definition of social intelligence (Bar-On, 2006; Barnes \& Sternberg, 1989) is somewhat more generic, and more closely overlaps with that of interpersonal competence (Spitzberg \& Cupach, 1989, 2002; Spitzberg, 2003). For example, Thorndike (1920) referred to social intelligence as the ability "to act wisely in human relations" (p. 228), and Albrecht (2004) referred to it as the capacity "to get along well with others and to get them to cooperate with you" (p. 30). Some of the most investigated components of social intelligence include social problem solving, awareness of and ability to regulate emotions, perspective taking, and inhibition of impulsive behavioral responses (Ford \& Tisak, 1983; Zins, Elias, Greenberg, \& Weissberg, 2000). Lastly, emotional intelligence refers to the individuals' ability to "identify their feelings and the feelings of others, regulate these feelings, and use the information provided by their feelings to motivate adaptive social behavior” (Salovey, Mayer, Goldman, Turvey, \& Palfai, 1995, p. 126). Emotional intelligence, thus, also shares many features with, and largely contributes to interpersonal competence.

According to Buhrmester et al. (1988), the multifaceted construct of interpersonal competence may be conceived of as the extent to which a person shows social and emotional intelligence, as well as specific behavioral or social skills (such as the ability to decode nonverbal communication and social expressivity) in various, social situations. Crucially, interpersonal functioning largely varies from one context to another: Different interpersonal situations may require different social skills, and a person's interpersonal functioning may vary also across multiple stages of the same relationship. For instance, while the ability to initiate relationships is central to finding a partner, being able to manage interpersonal conflict may be 


\section{Validity and Reliability of the Italian ICQ}

more relevant at later stages, so as to maintaining stable marital relationships (e.g., Convey \& Dengerink, 1984). As such, to deeply understand the construct of interpersonal competence, "it is necessary to identify different domains before studying the skills that are responsible for effective performance in each domain" (Buhrmester et al., 1988, p. 991).

In line with these considerations, and based on their review of the literature, Buhrmester et al. (1988) introduced the Interpersonal Competence Questionnaire (ICQ; Buhrmester et al., 1988), a 40-item self-report instrument measuring multiple aspects of interpersonal competence. More specifically, the ICQ addresses: 1) the respondent's ability to initiate social interactions and begin relationships (Initiation); 2) his/her ability to assert personal rights and express displeasure (Negative Assertion); 3) his/her ability to disclose personal information (Disclosure); 4) his/her ability to provide emotional support to others, and make them feel understood (Emotional Support); 5) his/her ability to manage interpersonal conflict and deal with disagreements in a positive way (Conflict Management). In each of these domains, a person may or may not show social skills, empathy, and social and/or emotional intelligence, thus demonstrating (or not) interpersonal competence. Although also other domains could be identified, according to Buhrmester et al. (1988) these ones provide "relatively comprehensive coverage of important interpersonal domains" (p. 992).

Given the relevance of the construct, and the lack of instruments specifically targeting these chief dimensions of interpersonal competence, it is not surprising that the ICQ has recently received increasing attention, and has been cross-validated into some non-U.S. cultures. For example, a German (Kanning, 2006), a Polish (Górska, 2011), and a French (Schlegel, Grandjean, \& Scherer, 2013) versions were recently introduced and examined. In Buhrmester et al.'s (1988) original studies, the internal consistency of the ICQ scales ranged from .77 to .87 


\section{Validity and Reliability of the Italian ICQ}

(Cronbach's alpha), and a series of factor analyses confirmed the hypothesized, five-factor structure of the ICQ. Very similar results were found with adult samples (ranging in age 18 to 40) with a Polish (Górska, 2011) and a German (Kanning, 2006) versions too. Validity also was demonstrated by numerous other investigations (for a review, see Kanning, 2006), using criteria such as emotional reactivity, social integration, coping, or interpersonal stress (e.g., BartleHaring \& Sabatelli, 1997; Gasteiger \& Klicpera, 1999; Gudleski \& Shean, 2000; Jackson, Flaherty, \& Kosuth, 2000). To date, however, no studies have yet investigated the ICQ in Italy.

\section{Aims and Hypotheses}

The current article describes the development and validation of an Italian-language version of the ICQ. Our main goal is to contribute to the study of the cross-cultural applicability of the instrument by investigating the validity and reliability of the ICQ within an Italian context. Two studies were conducted, and a total of 467 respondents (mostly women, ranging in age from 18 to 57), from three different Italian universities, contributed to this research. In line with the literature summarized above, we expected the Italian ICQ to demonstrate a five-factor structure, with good internal consistency, test-retest reliability, and convergent validity.

As for the convergent validity, based on the previous literature on the ICQ (for a review, see Kanning, 2006), as well as on our theoretical considerations, we expected that the Italian ICQ would correlate positively with empathy, psychological well-being, extraversion, openness, and agreeableness, but negatively with neuroticism and emotion dysregulation. More in detail, Initiation (i.e., the ability to initiate social interactions and begin relationships) was expected to correlate strongly and positively with extraversion, but negatively with neuroticism. Indeed, extraverted individuals tend to be open to new experiences, to enjoy human interactions, and to be gregarious and talkative (Costa \& McCrae, 1992), and therefore should be particularly prone 
to successfully starting new relationships (Buhrmester et al., 1988; Costa \& McCrae, 1992).

Conversely, neuroticism may inhibit social interactions in that anxiety and depression often decrease the willingness to start conversations and initiate new relationships (Riemann \& Allgöwer, 1993). Negative Assertion (i.e., the ability to assert personal rights and express displeasure) was expected to correlate positively with extraversion and emotional clarity, but negatively with agreeableness and neuroticism. In order to assert personal rights and displeasure with others, indeed, one needs to know the emotions he/she is experiencing (emotional clarity) and must be willing to fulfill his/her social needs (extraversion), even when these needs are not in line with others' expectations or preferences (agreeableness), and despite the anxiety that such situations may generate (neuroticism). Disclosure (i.e., the ability to disclose personal information) was expected to correlate with extraversion and openness, in that self-disclosure is a key component of social exchanges (extraversion) and it typically reflects a desire to opening up to others (openness). Emotional Support (i.e., the ability to provide emotional support to others, and make them feel understood) was hypothesized to positively correlate with empathy and conscientiousness. Indeed, empathy is crucial to being able to understand others and make them feel understood (e.g., Rogers, 1951), and conscientious individuals are prone to take social responsibility, and therefore also to commit to emotionally support others. Lastly, Conflict Management (i.e., the ability to manage interpersonal conflict and deal with disagreements in a positive way) was expected to correlate with agreeableness and empathy, because both the desire for social harmony (agreeableness) as well as the ability and/or willingness to empathize with the other's point of view (empathy) tend to facilitate peaceful resolutions of conflicts.

Study 1 translated the ICQ into Italian and tested its internal consistency, factor structure, and convergent validity. Study 2 examined its test-retest reliability. 


\section{Study 1}

\section{Method}

To adapt the ICQ into the Italian language we followed a classic translation-backtranslation procedure (Brislin, 1980; Geisinger, 2003; Van de Vijver \& Hambleton, 1996). Initially, a bilingual individual translated the English version of the ICQ into Italian, and then another bilingual individual - who was blind to the original version - back-translated the Italian version into English to address possible inconsistencies. At that point, the first author collaborated with an American researcher and clinician to evaluate the degree of congruence between the original and the back-translated English versions. Because no notable discrepancies emerged, the translation was deemed to be adequate and no additional modifications were made. The final, Italian version was then administered to a large sample of Italians, in order to investigate its validity and reliability. ${ }^{1}$

Recruitment Procedures and Participants. Participants were recruited at two Italian universities, one located in Milan and the other located in Rome. Before the beginning of a lecture (after approval by the respective institutional review board), students in class were informed about the opportunity to volunteer for a research study on psychology and personal relationships. More specifically, they were told that participation involved anonymous compilation of a number of questionnaires, and that if they chose to participate they could discontinue their participation at any time. Eligibility criteria included: (a) being Italian citizen, (b) being fluent in Italian, and (c) not receiving psychiatric therapy or psychiatric medications. All students in class decided to participate, and therefore all were asked to fill out the questionnaires described below (including a demographic form).

\footnotetext{
${ }^{1}$ To obtain a copy of the Italian ICQ, please contact the corresponding author via email.
} 
In all, 408 students, ranging in age from 18 to $57(M=22.6, S D=4.6)$, contributed to this study. About three quarters were women (74.1\%), and more than half were students of Psychology (62.5\%). About 90\% (i.e., 87.1\%) defined him/herself as “Caucasian”, with some individuals also defining themselves as "Hispanic" (8.3\%), “Asian" (1.3\%), "Indian” (.5\%), "Black" (.3\%), or "Other" (2.6\%); all indicated "Italian" to be their native language. ${ }^{2}$

Measures. The entire sample was administered the Italian version of the ICQ along with a number of other self-rating measures. These additional instruments served to measure constructs related (either directly or inversely) to interpersonal competence, i.e., empathy, emotion dysregulation, psychological well-being, and the five basic personality traits, i.e., openness, conscientiousness, extraversion, agreeableness, and neuroticism.

The Interpersonal Competence Questionnaire (ICQ; Buhrmester et al., 1988). The ICQ is comprised of 40 items addressing various social situations in which a person may or may not show social competence. Each item is measured on a 5-point Likert scale, and combination of individual item scores produces five scale scores covering different domains of interpersonal competence. As reported above, Buhrmester et al. (1988) defined these domains as (a) the ability to initiate relationships (Initiation, 8 items), (b) the ability to assert displeasure with others (Negative Assertion, 8 items), (c) the ability to disclose personal information (Disclosure, 8 items), (d) the ability to provide emotional support and advice (Emotional Support, 8 items), and (e) the ability to manage interpersonal conflict (Conflict Management, 8 items). For each scale, the higher the score, the higher the interpersonal competence of the respondent. The current study investigated internal consistency, factor structure, and convergent validity of the Italian

\footnotetext{
${ }^{2}$ These are valid percentages. Missing data are 7 cases for age, 2 cases for gender, and 21 cases for ethnicity.
} 
ICQ. Additional information on the psychometric properties of the Italian ICQ are therefore detailed below.

The NEO Five-Factor Inventory (NEO-FFI; McCrae \& Costa, 2004). The NEO-FFI is a shortened version (60 items) of the Revised NEO Personality Inventory (NEO PI-R; Costa \& McCrae, 1992), a well-known, self-rating instrument assessing the basic personality traits. More specifically, the NEO-FFI measures openness (12 items), conscientiousness (12 items), extraversion (12 items), agreeableness (12 items), and neuroticism (12 items). The validity and reliability of both the NEO PI-R and NEO-FFI is supported by numerous studies, conducted in various cultural contexts (see McCrae \& Costa, 2004, 2010; Sherry, Hewitt, Flett, Lee-Baggley, \& Hall, 2007).

The current study utilized the Italian version of the instrument, which was first introduced (embedded in its long version, i.e., the NEO PI-R) by Caprara, Barbaranelli, Hahn, and Comrey (2001). In our study, alphas were as follows: .68 (Openness), .72 (Conscientiousness), .63 (Extraversion), .62 (Agreeableness), and .75 (Neuroticism). Though at a first sight some of these values may appear slightly lower than ideal, it should be noted that: (a) it is not uncommon for the NEO inventories to achieve Cronbach alphas lower than .70 (for a review, see McCrae, Kurtz, Yamagata, \& Terracciano, 2011); and (b) the idea that alpha values should necessary be higher than .70 has been heavily criticized by psychometricians and statisticians (e.g., John \& Soto, 2007; Sijtsma, 2009). In short, as McCrae et al. (2011) pointed out, "Internal consistency seems to have little to do with the validity of NEO Inventory facets" (p. 20).

The Difficulties in Emotion Regulation Scale (DERS; Gratz \& Roemer, 2004). The DERS is a widely investigated, 36-item self-report scale measuring difficulties in emotion regulation. Each item is measured on a 5-point Likert scale, and combining the respondent's 
answers produces six dimensions of difficulties in emotion regulation: (a) nonacceptance of emotional responses (Nonacceptance, 6 items), (b) difficulties in engaging in goal-directed behavior (Goals, 5 items), (c) difficulties in controlling impulses (Impulse, 6 items), (d) lack of emotional awareness (Awareness, 6 items), (e) limited access to emotion regulation strategies (Strategies, 8 items), and (f) lack of emotional clarity (Clarity, 5 items). For each scale, the higher the score, the poorer the emotion regulation ability of the respondent.

In Gratz and Roemer's (2004) original study, internal consistency was .93 for the total score and $\geq .77$ for the subscales (Cronbach's alpha). In that same study, test-retest reliability and construct validity were also investigated, with the results further confirming the good psychometric properties of the DERS. Numerous international research projects also provide support for the validity and reliability of the DERS (e.g., Cho \& Hong, 2013; Dan-Glauser \& Scherer, 2013; Mitsopoulou, Kafetsios, Karademas, Papastefanakis, \& Simos, 2013; Ruganci \& Gençöz, 2010).

The current investigation used the Italian version of the DERS (Giromini, Velotti, de Campora, Bonalume, \& Zavattini, 2012), which has demonstrated good psychometric properties in several studies (e.g., de Campora, Giromini, Larciprete, Li Volsi \& Zavattini, 2014;

Giovannini et al., 2014; Giromini et al., 2012; Giromini, Brusadelli, Di Noto, Grasso \& Lang, 2015). In our sample, Cronbach's alphas were as follows: .86 (Nonacceptance), .86 (Goals), .87 (Impulse), .72 (Awareness), .90 (Strategies), .88 (Clarity), and .95 (Total DERS Score).

The Psychological General Well Being Index (PGWBI; Dupoy, 1977, 1984). The PGWBI is a 22-item self-rating instrument that measures psychological well-being. Each item is measured on a 6-point Likert scale, and combining the individual item scores generates six subscales indicative of quality of life with respect to (a) absence of anxiety (5 items), (b) absence 
of depressed mood (3 items), (c) positive well-being (4 items), (d) self-control (3 items), (e) general health (3 items), and (f) vitality (4 items). The higher the scores, the better the quality of life. In Dupoy’s (1984) initial work, internal consistency ranged from .72 to .88, and validity was demonstrated by significant correlations, in the expected direction, with several criteria related to stress, life satisfaction, and use of mental health care. More recent research works also support the validity and reliability of the PGWBI (e.g., Badia, Gutiérrez, Wiklund, \& Alonso, 1996; Naughton, \& Wiklund, 1993; Wool et al., 2000).

The current study used the Italian version of the PGWBI, which was introduced by Grossi, Masconi, Groth, Nievo, and Apolone (2002). In our study, Cronbach's alphas were: .84 (Absence of Anxiety), .76 (Absence of Depression), .84 (Positive well-being), .56 (Self-control), .59 (General health), .69 (Vitality), and .92 (Total PGWBI Score).

The Questionnaire of Cognitive and Affective Empathy (QCAE; Reniers, Corcoran, Drake, Shryane, \& Völlm, 2011). The QCAE is a 31-item, self-report instrument measuring five first-level dimensions of empathy, i.e., (a) perspective taking (10 items), (b) online simulation (of what another person is feeling) (9 items), (c) emotion contagion (4 items), (d) proximal responsivity (i.e., emotional responsivity in a close social context) (4 items) and (e) peripheral responsivity (i.e., emotional responsivity in a detached context) (4 items). While perspective taking and online simulation reflect a cognitive type of empathy, the other three dimensions measured by the QCAE reflect an affective type of empathy. Thus, in addition to the five firstlevel scores, the QCAE also produces two second-level scores, which namely measure (a) cognitive and (b) affective empathy. Furthermore, a global, total score may also be generated by summing up the scores of these second-level dimensions of empathy. 
Although the QCAE has been introduced only recently, its factor structure, reliability and validity (both construct and convergent validity) have already been verified in large samples of university students and employees. Thus, according to Reniers et al. (2011), this instrument can be considered to be a valid tool for assessing cognitive and affective empathy. However, the QCAE is so new that no Italian adaptations of the scale have yet been proposed, and no data on the validity and reliability of the QCAE in Italy have yet been published. Hence, we used a translation-back-translation procedure and generated an Italian QCAE to be used in our study. In our sample, Cronbach's alphas for the first-level scores were: .87 (Perspective taking), .83 (Online simulation), .73 (Emotion contagion), .64 (Proximal responsivity), and .58 (Peripheral responsivity). Cronbach's alphas for the second-level scores were: .80 (Cognitive empathy), and .81 (Affective empathy). The Total QCAE Score had a Cronbach's alpha of .87. A confirmatory factor analysis also confirmed that the factor structure proposed by Reniers et al. (2011) adequately fit the Italian data (a more detailed paper on the cross-cultural applicability of the QCAE is currently in preparation).

\section{Results}

Below we present data on the internal consistency, factor structure, and convergent validity of our Italian version of the ICQ. First, we show some basic, descriptive statistics, and then we report on the reliability and validity of the instrument.

ICQ Scores. The ICQ scores produced by our sample are shown in Table 1. To test whether men vs. women in our sample produced significantly different scores, we used Bonferroni procedures and set significance levels at $p=.01$ (i.e., .05 divided by 5) and $p=.002$ (i.e., .01 divided by 5) to ensure experimentwise error rates of .05 and .01 respectively. In line with findings observed by Buhrmester et al. (1988) and Górska (2011), only Emotional Support 


\section{Validity and Reliability of the Italian ICQ}

produced significant results. In fact, no significant gender differences emerged for Initiation, Negative Assertion, Disclosure, and Conflict Management, while women scored significantly higher than men on Emotional Support, $t(163.4)=4.88, p<.01, d=.59 .^{3}$

When compared to Buhrmester et al.' (1988) study, our Italian sample produced statistically significantly (after Bonferroni correction) lower scores on Disclosure, $t(816.6)=$ $4.05, p<.01, d=.28,{ }^{3}$ Emotional Support, $t(802.9)=7.35, p<.01, d=.51,{ }^{3}$ and Conflict Management, $t(813.9)=3.53, p<.01, d=.25 .^{3}$ Interestingly, the Polish student sample (Górska, 2011) also produced lower scores than Buhrmester et al.'s (1988) on both Emotional Support and Conflict Management, and with similar effect sizes ( $d=.64$ and $d=.28$ respectively).

The correlations between the five scales of the Italian ICQ are presented in Table 2. This correlation matrix is strikingly similar to that found in the original study (Buhrmester et al., 1988), as well as to those reported in the Polish and German validations of the instrument (Górska, 2011; Kanning, 2006). Taken together, thus, these findings provide some support to the equivalence between the Italian and the other available versions of the ICQ.

Internal Consistency. Internal consistency of the Italian ICQ was examined by calculating Cronbach's alphas and item-total correlations. As shown in Table 3, the internal consistency of the Italian ICQ is satisfactory, with Cronbach's alpha ranging from .77 (Negative Assertion) to .87 (Emotional Support). In Buhrmester et al.'s (1988) study, alphas ranged from .77 (Negative Assertion) to .86 (Emotional Support and Initiation), too. Once more, the statistics produced by the Italian sample are highly similar, virtually identical to those produced by previous research.

\footnotetext{
${ }^{3}$ Because homoscedasticity could not be assumed, Welch-Satterthwaite method was used to adjust degrees of freedom.
} 
Factor Structure. A confirmatory factor analysis (CFA) was tested to evaluate whether the factor structure identified by Buhrmester et al. (1988), and later confirmed by Górska (2011) and Kanning (2006), would also fit our Italian data. Accordingly, we specified five latent variables - corresponding to the five scales of the ICQ - and allowed them to correlate. Analyses were conducted with Lisrel 8.72 (Jöreskog \& Sörbom, 2005), using a maximum likelihood estimation method (Hu et al. 1992), and based on a listwise correlation matrix (for details on the advantages vs. disadvantages of this method, see Schafer \& Graham, 2002), for a total $N$ of 396.

All in all, goodness of fit statistics indicated that the tested model fit well with our data. In fact, the root mean square error of approximation (RMSEA) was .065 - indicative of a close to fair fit (Browne \& Cudeck 1993); both the comparative fit index (CFI) and the nonnormed fit index (NNFI) were above .90 (.95 and .94, respectively) - also suggesting a good fit (Bentler \& Bonett 1980); and the ratio of the value of chi-square $\left(\chi^{2}=1946.64\right)$ to its degrees of freedom (df $=730$ ) was $2.67-$ which further confirms that the fit was good (Watkins 1989). All factor loadings were $\geq .25$ (for details see Fig. 1).

Additional Analyses. Because the correlations between the five ICQ dimensions were substantial, in addition to the five-factor model described above (Model 1) we also tested two additional models. First, we tested a unidimensional model, in which only one general interpersonal competence factor was defined (Model 2). Next, we tested a hierarchical model, in which Initiation, Negative Assertion, Disclosure, Emotional Support, and Conflict Management were defined as facets of an overall construct of interpersonal competence (Model 3). Model 2 produced the following goodness of fit statistics: $\mathrm{RMSEA}=.130 ; \mathrm{CFI}=.88 ; \mathrm{NNFI}=.87 ; \chi^{2}=$ $5365.99 ; \mathrm{df}=740 ; \chi^{2} / \mathrm{df}=7.25$. Model 3 produced the following goodness of fit statistics: RMSEA $=.069 ; \mathrm{CFI}=.94 ; \mathrm{NNFI}=.94 ; \chi^{2}=2102.18 ; \mathrm{df}=735 ;$ chi-square $/ \mathrm{df}=2.86$. Thus, 
while Model 2 did not provide a good fit, Model 3 fit fairly well our data. However, Model 1 still provided a significantly better fit than did Model $2, \chi_{(5)}^{2}=155.54, \mathrm{p}<.001$.

Convergent Validity. Convergent validity analyses are reported in Table 4. Because 135 correlation were tested, we used Bonferroni procedures and set significance levels at $p=.00037$ (i.e., .05 divided by 135) and $p=.000074$ (i.e., .01 divided by 135) to ensure actual alpha levels of .05 and .01. In line with our hypotheses, Initiation correlated positively with extraversion and negatively with neuroticism, Negative Assertion correlated positively with extraversion and negatively with neuroticism and the DERS Clarity subscale, Disclosure correlated positively with openness and extraversion, Emotional Support correlated positively with conscientiousness and empathy, and Conflict Management correlated positively with agreeableness and empathy. Consistent with the idea that social functioning is important to mental health and psychological wellbeing, the ICQ scales generally correlated positively with the extraversion and openness scales of the NEO-FFI, with the PGWBI scales measuring well-being, and with the total QCAE score, and negatively with the neuroticism scale of the NEO-FFI and with the DERS scales. Taken together, thus, these findings provide evidence for the convergent validity of the Italian ICQ.

\section{Study 2}

Study 2 examined the test-retest reliability of the Italian ICQ. A student sample of 59 adults contributed to this study. About one third (18, i.e., 30.5\%) was recruited at University of Milano-Bicocca, about two thirds (41, i.e., 69.5\%) were recruited at University of Turin.

\section{Method}

Recruitment Procedures and Participants. Before the beginning of a lecture, students in class were invited to anonymously complete a self-report questionnaire. Inclusion and 
exclusion criteria were the same as those used in Study 1, and participation also was on a voluntarily basis. All students in class agreed to participate, and therefore all were invited to write on top of the questionnaire an invented identification number, and to keep note of it. About one month later, before a subsequent lesson of the same class, students in class were asked to fill out the ICQ again, and to report on the form the same identification number they chose for their first administration. The 59 students who were present at both of the administrations were included in the analyses. This sample size (i.e., $n=59$ ) is bigger than that used by Buhrmester et al. (1988) to evaluate the test-retest reliability of the ICQ $(n=31)$ in their original article, and it is consistent with current recommendations (e.g., Hertzog, 2008; Walter, Eliasziw, \& Donner, 1998) and practice (e.g., Calamia, Markon, \& Tranel, 2013; Paiva et al., 2014) in psychology and medicine. Age ranged from 19 to 34 years $(M=22.5 ; S D=2.1)$, most of them $(49$, i.e., $83.1 \%)$ were women, and all defined themselves as "Caucasian."

\section{Results}

Intraclass correlation coefficients (ICCs) were calculated for all ICQ scales so as to examine test-retest reliability. According to the suggested benchmarks (Cicchetti 1994; Cicchetti \& Sparrow 1981; Fleiss 1981), ICCs above .74 are excellent, ICCs between .60 and .74 are good, ICCs between .40 and .59 are fair, and ICCs below .40 are poor. Taken together, the results of Study 2 indicated that the Italian ICQ possesses fair to excellent inter-rater reliability. In fact, ICCs were .81 for Initiating Relationships, .73 for Emotional Support, .79 for Asserting Influence, .80 for Self-Disclosure, and .55 for Conflict Resolution.

\section{General Discussion}

Interpersonal competence plays a key role in our lives, and is important to our mental health (Kim et al., 1997; Muralidharan et al., 2010; Skodol et al., 2005). In recent years, efforts 
were made to empirically measure interpersonal competence, and a Polish (Górska, 2011), a French (Schlegel et al., 2013), and a German (Kanning, 2006) versions of the Interpersonal Competence Questionnaire (ICQ; Buhrmester et al., 1988) have been investigated. Because no studies on the ICQ had yet been conducted in Italy, we developed an Italian version of the ICQ and investigated its psychometric properties with two independent student samples. Study 1 tested factor structure, internal consistency, and convergent validity; Study 2 investigated testretest reliability. Taken together, the results of both these studies support the cross-cultural applicability of the ICQ, as well as its validity and reliability.

Factor structure and internal consistency analyses of Study 1 produced strikingly similar results to those originally reported by Buhrmester et al. (1988), and later replicated by Górska (2011) and Kanning (2006) with the German and Polish versions. Thus, one may anticipate that the ICQ would be applicable to various cultures, with small changes from one country to another. Future research, however, should further test this hypothesis by investigating nonwestern countries. Indeed, collectivistic and individualistic cultures are known to differ from each other on several psychological aspects linked to interpersonal competence, such as personality traits (e.g., Matsumoto, 2006), coping (e.g., Bjorck, Cuthbertson, Thuman, \& Lee, 2001; Morling, Kitayama, \& Miyamoto, 2003; Taylor, Sherman, Kim, Jarcho, \& Takagi, 2004; Tweed, White, \& Lehman, 2004), and emotional expression (Matsumoto \& Kupperbusch, 2001). Thus, whether the ICQ may or not be applicable also to collectivistic countries still awaits further research. Moreover, given the relatively high relationship observed between the five dimensions of the ICQ, future research might also explore the possibility to introduce a global, total ICQ score, aimed at providing relatively broad information on a person's interpersonal competence. 


\section{Validity and Reliability of the Italian ICQ}

Examination of the convergent validity analyses allows for some additional, interesting considerations. As expected, the ICQ scales generally correlated positively with openness, extraversion, well-being, and empathy, and negatively with neuroticism and emotion dysregulation. This finding is well in line with previous studies indicating that interpersonal competence is central to human well-being and mental health, as it mediates the process of daily stress generation (Cummings et al., 2013) and associates with various personality disorder symptoms (Muralidharan et al., 2010). Our more detailed predictions specifically concerning Initiation, Negative Assertion, Disclosure, Emotional Support, and Conflict Management were confirmed too. Taken together, thus, these findings provide additional support to the convergent validity of the ICQ.

A somewhat unpredicted, but interesting finding is that interpersonal competence associated more strongly with cognitive, rather than affective empathy. In fact, the average correlation between the QCAE cognitive empathy and the ICQ scales was .37, while the average correlation between the ICQ scales and the QCAE affective empathy scale was only .12. Also, while all ICQ scales correlated significantly with cognitive empathy, only Emotional Support significantly correlated with affective empathy. Thus, one may speculate that to successfully interact with others, cognitively understanding the feelings and thoughts of the persons we relate with might be more important than experiencing and sharing their emotional states. Future research might further investigate this hypothesis.

The relatively strong correlation between Initiation and Negative Assertion $(r=.62)$ also is noteworthy. In Buhrmester et al.' (1988) study these two domains correlated .47, in Kanning's (2006) they correlated .43, and in Górska's (2011).61. Thus, our findings are somewhat in line with previous research, and closely resemble those reported with the Polish ICQ. A possible 
explanation for this phenomenon is that individuals with good Initiation skills might be particularly prone to assert personal rights and express displeasure in that they are not too preoccupied to become or feel lonely. Put simply, because they know they will be able to initiate new relationships, they do not feel the need to please others in order to be accepted by them. This explanation would be supported by the fact that both Initiation and Negative Assertion positively correlated with extraversion, but did not correlate or correlated negatively with Agreeableness (Table 4). Another possible explanation is that individuals with good Initiation skills might have more opportunities to interact with others, and this would give them more chances to learn how to assert their personal rights. Indeed, as Buhrmester et al. (1988) pointed out, "people who are skilled in one context may have greater opportunity to become skilled in other contexts that arise from earlier success" (p. 998). Future research might further investigate these hypotheses too.

As reviewed above, the construct of interpersonal competence is closely related to psychological constructs such as social and emotional intelligence, empathy, and social skills. In general, one may say that all these competences and skills are important to promote wellbeing and mental health. However, it is important to appreciate that interpersonal competence is not a unitary and stable characteristic: It varies from one context to another and also across multiple stages of the same relationship. Thus, researchers interested in investigating relatively broad and stable personality features might find it useful to utilize instruments, such as the Trait MetaMood Scale (TMMS; Salovey, Mayer, Goldman, Turvey, \& Palfai, 1995) or the Troms $\varnothing$ Social Intelligence Scale (TSIS; Silvera \& Martinussen, 2001), which measure constructs such as emotional and social intelligence. Conversely, researchers interested in evaluating the specific domains and stages of interpersonal functioning, might find it more useful to adopt the ICQ. 


\section{Validity and Reliability of the Italian ICQ}

Lastly, this article also provides information on the test-retest reliability of ICQ. In Buhrmester et al.'s (1988) developmental work, the ICQ demonstrated adequate test-retest stability, with Pearson correlation $r$ 's ranging from .69 to .89 . None of the non-U.S. studies conducted with the ICQ (i.e., Górska, 2011; Kanning, 2006, Schlegel et al., 2013), however, had yet replicated this finding, in that none addressed test-retest reliability. Our Study 2, thus, is the first to confirm the fair to excellent temporal stability of the ICQ also from a non-U.S. context.

Even though these findings strongly support the cross-cultural applicability of the ICQ, a number of limitations should be kept in mind, while reading this article. First, our sample was made up of students, with a majority of women, which somewhat limits the generalizability of the results. Even though Buhrmester et al. (1988) original study as well as many other ICQ validation studies also used student-only samples, future investigations encompassing community samples would certainly be beneficial. Moreover, additional research on crosscultural differences on the mean ICQ scores also would be interesting, given that our Italian sample produced some different mean scores compared to Buhrmester et al.'s (1988) data. Second, our studies only implemented self-report instruments, which are known to be subject to social desirability and other limitations. To overcome this problem, future research might attempt to investigate whether the ICQ also correlates with other external and more ecologically valid criteria. For example, one may conduct an experiment in which a research assistant spends some time in a waiting room with a participant, making him/her believe that he/she is a participant too. Then he/she might follow a standardized conversation so as to experimentally test the five ICQ domains, for example by generating a mild conflict (to test Conflict Management) or by discussing an emotionally loaded, personal situation (to test Emotional Support). Alternatively, one might also investigate the relationship of the five ICQ domains to performance-based 


\begin{abstract}
Validity and Reliability of the Italian ICQ
instruments, behavioral measures or ratings by others. For instance, one might whether individuals with higher Disclosure scores would be more self-revealing (e.g., would produce more responses) when administered the Rorschach Inkblot Test (Rorschach, 1921), or whether individuals with higher Emotional Support scores would achieve higher scores on the Safe Haven - Caregiving scale when tested with the Current Relationship Interview (Crowell \& Owens, 1998). Finally, it would also be interesting to more thoroughly investigate the clinical utility of the instrument, for example by testing whether individuals affected by personality disorders produce lower ICQ scores, compared to our student sample. Indeed, because being aware of a client's interpersonal functioning is important to treatment planning (Muralidharan et al., 2010), it is reasonable to believe that the ICQ might serve as a valuable psychological tool also in clinical practice.
\end{abstract}


Validity and Reliability of the Italian ICQ

\section{References}

Albrecht K. (2004). Social intelligence: Beyond IQ. Training, 41, $28-31$.

Astin, H. S. (1967). Assessment of empathic ability by means of a situational test. Journal of Counseling Psychology, 14, 57-60.

Badia, X., Gutiérrez, F., Wiklund, I., \& Alonso, J. (1996). Validity and reliability of the Spanish version of the Psychological General Well-Being Index. Quality of Life Research, 5(1), 101-108.

Barnes, M.L., \& Sternberg, R.J. (1989). Social intelligence and decoding of nonverbal cues. Intelligence, 13, 263-287.

Bar-On, R. (2006). The Bar-On model of emotional social intelligence (ESI). Psicothema, 18, $13-25$.

Bartle-Haring, S., \& Sabatelli, R. M. (1997). Emotional reactivity toward parents and interpersonal competence: Differences across gender and type of relationship. Journal of Youth and Adolescence, 26 (4), 399-413.

Bartle-Haring, S., \& Sabatelli, R. M. (1997). The relationship between emotional reactivity towards parents and interpersonal competence in same-sex friend and dating partner relationships: an exploration of gender differences in two samples. Journal of Youth and Adolescence, 26, 399-413.

Bentler, P. M., \& Bonett, D. G. (1980). Significance tests and goodness-of-fit in the analysis of covariance structures. Psychological Bulletin, 88, 588-600.

Bjorck, J. P., Cuthbertson, W., Thurman, J. W., \& Lee, Y. S. (2001). Ethnicity, coping, and distress among Korean Americans, Filipino Americans, and Caucasian Americans. Journal of Social Psychology, 141, 421-442. 
Brislin, R. W. (1980). Translation and content analysis of oral and written material. In H.C. Triandis \& J.W. Berry (Eds.), Handbook of cross-cultural psychology (Vol.1) (pp. 389444). Boston, MA: Allyn \& Bacon.

Browne, M. W., \& Cudeck, R. (1993). Alternative ways of assessing model fit. In: Bollen, K. A. \& Long, J. S. (Eds.) Testing Structural Equation Models. pp. 136-162. Beverly Hills, CA: Sage.

Buhrmester, D., Furman, W., Wittenberg, M.T., \& Reis, H.T. (1988). Five Domains of Interpersonal Competence in Peer Relationships. Journal of Personality and Social Psychology, 55(6), 991-1008. DOI: 10.1037/0022-3514.55.6.991.

Cairns, R.B., Cairns, B.D., \& Neckerman, H.J. (1989). Early School Dropout: Configurations and Determinants. Child Development, 60(6), 1437-1452.

Calamia, M., Markon, K., \& Tranel, D. (2013). The Robust Reliability of Neuropsychological Measures: Meta-Analyses of Test-Retest Correlations. The Clinical Neuropsychologist, 27, 1077-1105.

Caprara, G.V., Barbaranelli, C., Hahn, R., \& Comrey, A.L. (2001). Factor analyses of the NEOPI-R inventory and the Comrey Personality Scales in Italy and the United States. Personality and Individual Differences, 30, 217-228.

Cho, Y., \& Hong, S. (2013). The New Factor Structure of the Korean Version of the Difficulties in Emotion Regulation Scale (K-DERS) Incorporating Method Factor. Measurement and Evaluation in Counseling and Development. Advance Online Publication, DOI: $10.1177 / 0748175613484033$ 
Validity and Reliability of the Italian ICQ

Cicchetti, D. V. (1994). Guidelines, criteria, and rules of thumb for evaluating normed and standardized assessment instruments in psychology. Psychological Assessment, 6, 284290.

Cicchetti, D. V., \& Sparrow, S. S. (1981). Developing criteria for establishing the interrater reliability of specific items in a given inventory. American Journal of Mental Deficiency, $86,127-137$.

Convey, M. K., \& Dengerink, H. A. (1984). Development and validation of a measure of heterosexual conflict resolution ability (Relational Behavior Survey). Behavioral Assessment, 6, 323-332.

Cortina, J. M. (1993) What is coefficient alpha? An examination of theory and applications. Journal of Applied Psychology, 78, 98-104.

Costa, P. T., \& McCrae, R. R. (1992). Revised NEO Personality Inventory (NEO-PI-R) and NEO Five-Factor Inventory (NEO-FFI) professional manual. Odessa, FL: Psychological Assessment Resources.

Crowell, J. A., \& Owens, G. (1998). Manual for the Current Relationship Interview and scoring system. Stony Brook: State University of New York.

Cummings, J. A, Hayes, A. M., Cohen, L. H., Laurenceau, J. P., Saint, D. S., \& Gricol, K. (2013). Interpersonal Competence and Daily Stress Generation in Individuals with Avoidant Personality Disorder Symptoms. Journal of Social and Clinical Psychology, 32 (2), 135-158.

Dan-Glauser, E. S. \& Scherer, K. R. (2013). The Difficulties in Emotion Regulation Scale (DERS): Factor structure and consistency of a French translation. Swiss Journal of Psychology, 72(1), 5-11. DOI: 10.1024/1421-0185/a000093. 
Validity and Reliability of the Italian ICQ

De Campora, G., Giromini, L., Larciprete, G., Li Volsi, V., \& Zavattini, G. C. (2014). The Impact of Maternal Overweight and Emotion Regulation on Early Eating Behaviors. Eating Behaviors, 15 (3), 403-409. DOI: 10.1016/j.eatbeh.2014.04.013

Ditommaso, E., Brannen-McNulty, C., Ross, L., \& Burgess, M. (2003). Attachment styles, social skills and loneliness in young adults. Journal of Personality and Individual Differences, 35, 303-312. DOI: 10.1016/S0191-8869(02)00190-3.

Dupuy, H.J. (1977). The General Well-being Schedule. In: Measuring health: a guide to rating scales and questionnaire. 2nd. McDowell, I., Newell, C., editor. USA: Oxford University Press., pp. 206-213.

Dupuy, H.J. (1984). The Psychological General Well-Being (PGWB) Index. In: Assessment of quality of life in clinical trials of cardiovascular therapies. Wenger, N., editor. New York: Le Jacq, pp. 170-183.

Fleiss, J. L. (1981). Statistical methods for rates and proportions (2nd ed.). New York, NY: Wiley.

Ford, M.E., \& Tisak, M.S. (1983). A further search for social intelligence. Journal of Eductaional Psychology, 75, 197-206.

Frisbie, S.H., Fitzpatrick, H., Feng, D., \& Crawford, D. (2000). Women's personality traits, interpersonal competence and affection for dating partners: A test of the contextual model. Social Behavior and Personality, 28(6), 585-594.

Gasteiger-Klicpera, B., \& Klicpera, C. (1999). Social competence of children with peer relationship problems. Zeitschrift fur Kinder und Jugendpsychiatrie und Psychotherapie, 27(2), 93-102. 
Geisinger, K. F. (2003). Testing and assessment in cross-cultural psychology. In J. R. Graham, J. A. Naglieri \& I. B. Weiner (Eds.), Handbook of psychology (Vol. 10). Assessment Psychology (pp. 95-118). New Jersey, NJ: John Wiley \& Sons.

Giovannini, C., Giromini, L., Bonalume, L., Tagini, A., Lang, M., \& Amadei, G. (2014). The Italian Five Facet Mindfulness Questionnaire: A contribution to its Validity and Reliability. Journal of Psychopathology and Behavioral Assessment, 36, 415-423, DOI: 10.1007/s10862-013-9403-0.

Giromini, L., Brusadelli, E., Di Noto, B., Grasso, R., \& Lang, M. (2015). Measuring Psychological Mindedness: Validity, Reliability, and Relationship with Psychopathology of an Italian Version of the Balanced Index of Psychological Mindedness. Psychoanalytic Psychotherapy. Advance Online Publication, DOI: 10.1080/02668734.2015.1006666.

Giromini, L., Velotti, P., De Campora, G., Bonalume, L., \& Zavattini, G. C. (2012). Cultural Adaptation of the Difficulties in Emotion Regulation Scale: Reliability and Validity of an Italian Version. Journal of Clinical Psychology, 68(9), 989-1007. DOI: 10.1002/jclp.21876.

Górska, M. (2011). Psychometric Properties of the Polish Version of the Interpersonal Competence Questionnaire (ICQ-R). European Journal of Psychological Assessment, 27(3), 186-192.

Gratz, K. L., \& Roemer, L. (2004).Multidimensional assessment of emotion regulation and dysregulation: Development, factor structure, and initial validation of the difficulties in emotion regulation scale. Journal of Psychopathology and Behavioral Assessment, 26, 41-54. 
Validity and Reliability of the Italian ICQ

Grossi E., Masconi, P., Groth, N., Nievo, M., \& Apolone, G. (2002). Il questionario psychological general well being. Versione Italiana. Versione 0.2, Milan: Marzo.

Gudleski, G.D., \& Shean, G.D. (2000). Depressed and nondepressed students: Differences in interpersonal perceptions. Journal of Psychology, 134(1), 56-62.

Hertzog, M. A. (2008). Considerations in Determining Sample Size for Pilot Studies. Research in Nursing \& Health, 31, 180-191.

Jackson, T., Flaherty, S.R., \& Kosuth, R. (2000). Culture and self-presentation as predictors of shyness among japanese and american female college students. Perceptual and Motor Skills, 90(2), 475-482.

John, O. P., Soto, C. J. (2007). The importance of being valid: Reliability and the process of construct validation. In: Robins, RW.; Fraley, RC.; Krueger, RF., editors. Handbook of research methods in personality psychology. Guilford; New York: Pp. 461-494.

Jöreskog, K.G., \& Sörbom, D. (2005). LISREL 8.72: Interactive LISREL for MS Windows. Lincolnwood, IL: Scientific Software International, Inc.

Kanning, U. P. (2006). Development and validation of a German-language version of the Interpersonal Competence Questionnaire (ICQ). European Journal of Psychological Assessment, 22(1), 43-51.

Kim, Y., Pilkonis, P.A., \& Barkham, M. (1997). Confirmatory factor-analysis of the personalitydisorder subscales from the inventory of interpersonal problems. Journal of Personality Assessment, 69(2), 284-296.

Lamke, L., Sollie, D., Durbin, R., \& Fitzpatrick, J. (1994). Masculinity, femininity, and relationship satisfaction: The mediating role of interpersonal competence. Journal of Social and Personal Relationships, 11, 537-556. 
Lieberman, R. P. (1982). Assessment of social skills. Schizophrenia bulletin, 8 (1), 62-84.

Matsumoto, D. (2006). Are cultural differences in emotion regulation mediated by personality traits? Journal of Cross-Cultural Psychology, 37 (4), 421-437.

Matsumoto, D., \& Kupperbusch, C. (2001). Idiocentric and allocentric differences in emotional expression and experience. Asian Journal of Social Psychology, 4, 113-131.

McCrae, R. R., \& Costa, P. T., (2010). NEO Inventories: Professional manual. Lutz, FL: Psychological Assessment Resources, Inc.

McCrae, R. R., Kurtz, J. E., Yamagata, S., \& Terracciano, A. (2011). Internal consistency, retest reliability, and their implications for personality scale validity. Personality and Social Psychology Review, 15, 28-50.

McCrae, R.R., \& Costa, P.T. (2004). A contemplated revision of the NEO Five-Factor Inventory. Personality and Individual Differences, 36 (3), 587-596. DOI:10.1016/S01918869(03)00118-1

Mitsopoulou, E., Kafetsios, K., Karademas, E., Papastefanakis, E., \& Simos, P.G. (2013). The Greek Version of the Difficulties in Emotion Regulation Scale: Testing the Factor Structure, Reliability and Validity in an adult Community Sample. Journal of Psychopathology and Behavioral Assessment, 35, 123-131.

Morling, B., Kitayama, S., \& Miyamoto, Y. (2003). American and Japanese women use different coping strategies during normal pregnancy. Personality and Social Psychology Bulletin, $29,1533-1546$.

Muralidharan, A., Sheets, E.S., Madsen, J., Craighead, L.W., \& Craighead, E. (2010). Interpersonal Competence Across Domains: Relevance to Personality Pathology. Journal of Personality Disorders, 25(1), 16-27. 
Naughton, M.J., \& Wiklund, I. (1993). A critical review of dimension-specific measures of health-related quality of life in cross-cultural research. Quality of Life Research, 2(6), $397-432$.

Paiva, C. E., Barroso, E. M., Carneseca, E. C., de Pádua Souza, C., Dos Santos, F. T., Mendoza López, R. V., \& Ribeiro Paiva, S. B. (2014). A critical analysis of test-retest reliability in instrument validation studies of cancer patients under palliative care: a systematic review. BMC Medical Research Methodology, 14, 8. DOI: 10.1186/1471-2288-14-8.

Reniers, R.L., Corcoran, R., Drake, R., Shryane, N.M., Völlm, B.A. (2011). The QCAE: a Questionnaire of Cognitive and Affective Empathy. Journal of Personality Assessment, 93(1), 84-95. DOI: 10.1080/00223891.2010.528484.

Riemann, R., \& Allgöwer, A. (1993). Eine deutschasprachige Fassung des "Interpersonal Competence Questionnaire” (ICQ) [A German version of the Interpersonal Competence Questionnaire (ICQ)]. Zeitschrift für Differentielle und Diagnostiche Psychologie, 14, 153-163.

Riggio, R.E., \& Taylor, S.J. (2000). Personality and communication skills as predictors of hospice nurse performance. Journal of Business and Psychology, 15, 347-355.

Rogers, C. R. (1951). Client-centered therapy: Its current practice, implications and theory. Boston: Houghton-Mifflin.

Rorschach, H. (1921). Psychodiagnostik. Bern: Bircher.

Ruganc1, R. N., \& Gencöz, T. (2010). Psychometric properties of a Turkish version of the difficulties in emotion regulation scale. Journal of Clinical Psychology, 66, 4, 442-455.

Salovey, P., Mayer, J. D., Goldman, S. L., Turvey, C., \& Palfai, T. P. (1995). Emotional attention, clarity, and repair: Exploring emotional intelligence using the Trait MetaMood 
Validity and Reliability of the Italian ICQ

Scale. In J. W. Pennebaker (Ed.), Emotion, disclosure, and health (pp. 125-154).

Washington, DC: American Psychological Association.

Schafer, J.L., \& Graham, J.W. (2002). Missing data: our view of the state of the art. Psychological Methods, 7(2), 147-77.

Schlegel, K., Grandjean, D., \& Scherer, K.R. (2013). Constructs of social and emotional effectiveness: Different labels, same content? Journal of Research in Personality, 47, $249-253$.

Segrin, C. (1990). A meta-analytic review of social skill deficits associated with depression. Communication Monographs, 57, 292-308.

Segrin, C. (1993). Social skills deficits and psychosocial problems: Antecedent, concomitant, or consequent? Journal of Social and Clinical Psychology, 12, 336-353.

Segrin, C. (2001). Interpersonal processes in psychological problems. New York: Guilford Press.

Sherry, S. B., Hewitt, P. L., Flett, G. L., Lee-Baggley, D. L., \& Hall, P. A. (2007). Trait perfectionism and perfectionistic self-presentation in personality pathology. Personality and Individual Differences, 42 (3), 477-490. DOI:10.1016/j.paid.2006.07.026.

Sijtsma K. (2009). On the use, the misuse, and the very limited usefulness of Cronbach's alpha. Psychometrika, 74, 107-120.

Silvera, D. H., Martinussen, M., \& Dahl, T. I. (2001). The Troms $\varnothing$ Social Intelligence Scale, a self-report measure of social intelligence. Scandinavian Journal of Psychology, 42, 313320. 
Spitzberg, B. H. (2003). Methods of interpersonal skill assessment. In J. O. Greene \& B. R. Burleson (Eds.), Handbook of communication and social interaction skills. Mahwah, NJ: Erlbaum. Pp. 93-134.

Spitzberg, B. H., \& Cupach, W. R. (1989). Handbook of interpersonal competence research. New York: Springer-Verlag.

Spitzberg, B. H., \& Cupach, W. R. (2002). Interpersonal skills. In M. L. Knapp \& J. A. Daly (Eds.), Handbook of interpersonal communication. ( $3^{\text {rd }}$ ed.) London: Sage Pp. 564-612.

Taylor, S.E., Sherman, D.K., Kim, H.S., Jarcho, J., \& Takagi, K.(2004). Culture and social support: Who seeks it and why? Journal of Personality and Social Psychology, 87, 354362.

Thorndike, E.L. (1920). Intelligence and its use. Harper's Magazine, 140, 227-235.

Tweed, R. G., White, K., \& Lehman, D. R. (2004). Culture, stress, and coping: Internally- and externally-targeted control strategies of European Canadians, east Asian Canadians, and Japanese. Journal of Cross-Cultural Psychology, 35, 652-668.

Van de Vijver, F., \& Hambleton, R. K. (1996). Translating tests: Some practical guidelines. European Psychologist, 1, 89-99.

Walter, D. S., Eliasziw, M., \& Donner, A. (1998). Sample size and optimal design for reliability studies. Statistics in Medicine, 17, 101-110.

Watkins, CJCH (1989). Learning from delayed rewards. Cambridge: King's College.

Wispe, L. (1986). The distinction between sympathy and empathy: To call forth a concept, a word is needed. Journal of Personality and Social Psychology, 50, 314-321. 
Validity and Reliability of the Italian ICQ

Wool, C., Cerutti, R., Marquis, P., Cialdella, P., Hervié, C., \& Italian Study Group on Qulity of Life, ISGQL (2000). Psychometric validation of two Italian quality of life questionnaires in menopausal women. Maturitas, 35(2), 129-142.

Zins, J.E., Elias, M.J., Greenberg, M.T., \& Weissberg, R.P. (2000). Preventing school problems promoting school success: Strategies and programs that work. Bethesda, MD: National Association of School Psychologists. 
Validity and Reliability of the Italian ICQ

Table 1. Descriptive Statistics for the Italian ICQ Scales, among Men, Women, and Entire Sample.

\begin{tabular}{|c|c|c|c|c|c|c|c|c|c|c|c|c|}
\hline & \multicolumn{4}{|c|}{$\operatorname{Men}(n=105)$} & \multicolumn{4}{|c|}{ Women $(n=301)$} & \multicolumn{4}{|c|}{ Entire Sample $(N=408)$} \\
\hline & $M$ & $S D$ & Skew & Kurtosis & $M$ & $S D$ & Skew & Kurtosis & $M$ & $S D$ & Skew & Kurtosis \\
\hline Initiation & 3.28 & .71 & -.35 & -.29 & 3.33 & .78 & -.56 & .57 & 3.31 & .76 & -.51 & .42 \\
\hline Negative Assertion & 3.31 & .65 & -.76 & 1.03 & 3.39 & .62 & -.74 & 1.38 & 3.37 & .63 & -.74 & 1.25 \\
\hline Disclosure & 3.01 & .74 & -.14 & .26 & 3.03 & .75 & -.06 & .07 & 3.03 & .74 & -.08 & .11 \\
\hline Emotional Support & 3.54 & .71 & -.32 & -.09 & 3.92 & .62 & -1.12 & 2.41 & 3.82 & 67 & -.87 & 1.16 \\
\hline Conflict Management & 3.31 & .70 & -.26 & -.07 & 3.35 & .62 & -.21 & -.10 & 3.34 & .64 & -.24 & -.05 \\
\hline
\end{tabular}

Note. Two cases were missing gender information. 
Validity and Reliability of the Italian ICQ

Table 2. Correlations between the Five Scales of the Italian ICQ.

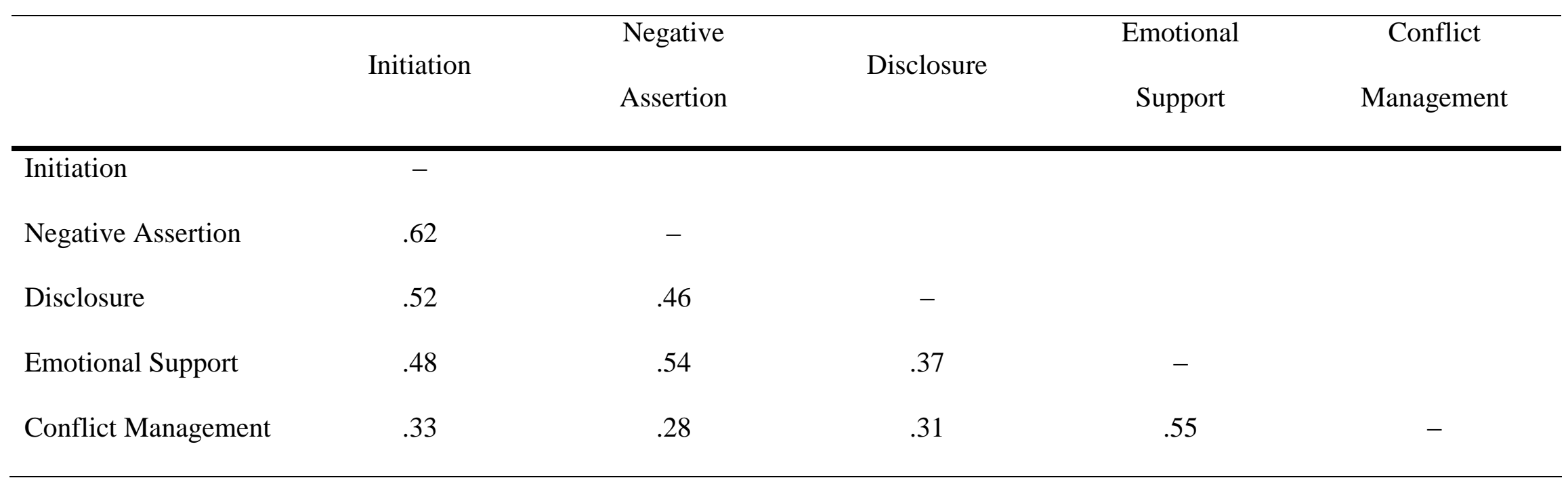

Note. All correlations are statistically significant at $p<.01$ after Bonferroni correction (i.e., uncorrected $p<.001$ ). 
Validity and Reliability of the Italian ICQ

Table 3. Internal Consistency Reliability Analyses for the Italian ICQ.

\begin{tabular}{lccc}
\hline & $\begin{array}{c}\text { No. of } \\
\text { items }\end{array}$ & $\begin{array}{c}\text { Cronbach's } \\
\text { alpha }\end{array}$ & $\begin{array}{c}\text { Range of item-total } \\
\text { correlations }\end{array}$ \\
\hline Initiation & 8 & .86 & $.62-.81$ \\
Negative Assertion & 8 & .77 & $.40-.70$ \\
Disclosure & 8 & .81 & $.48-.80$ \\
Emotional Support & 8 & .87 & $.62-.78$ \\
Conflict Management & 8 & .78 & $.46-.73$ \\
\hline
\end{tabular}


Validity and Reliability of the Italian ICQ

Table 4. Convergent Validity Analyses for the Italian ICQ.

\begin{tabular}{|c|c|c|c|c|c|}
\hline & Initiation & $\begin{array}{l}\text { Negative } \\
\text { Assertion }\end{array}$ & Disclosure & $\begin{array}{c}\text { Emotional } \\
\text { Support }\end{array}$ & $\begin{array}{c}\text { Conflict } \\
\text { Management }\end{array}$ \\
\hline \multicolumn{6}{|l|}{ NEO-FFI } \\
\hline Openness & $.31^{* *}$ & $.24^{* *}$ & $.18^{*}$ & $.24^{* *}$ & .08 \\
\hline Conscientiousness & .11 & $.33^{* *}$ & .08 & $.34^{* *}$ & $.24^{* *}$ \\
\hline Extraversion & $.54^{* *}$ & $.45^{* *}$ & $.37^{* *}$ & $.31^{* *}$ & .13 \\
\hline Agreeableness & -.06 & -.16 & .05 & .13 & $.37^{* *}$ \\
\hline Neuroticism & $-.35^{* *}$ & $-.35^{* *}$ & -.14 & $-.20^{* *}$ & $-.25^{* *}$ \\
\hline \multicolumn{6}{|l|}{ DERS } \\
\hline Nonacceptance & $-.22^{* *}$ & $-.22^{* *}$ & -.16 & $-.21^{* *}$ & -.15 \\
\hline Goals & -.13 & -.17 & -.10 & -.11 & -.13 \\
\hline Impulse & -.14 & $-.18^{*}$ & -.08 & $-.26^{* *}$ & $-.26^{* *}$ \\
\hline Awareness & -.16 & $-.22^{* *}$ & -.17 & $-.28^{* *}$ & -.13 \\
\hline Strategies & $-.27^{* *}$ & $-.31^{* *}$ & -.17 & $-.26^{* *}$ & $-.24^{* *}$ \\
\hline Clarity & $-.23^{* *}$ & $-.36^{* *}$ & $-.25^{* *}$ & $-.24^{* *}$ & $-.21^{* *}$ \\
\hline Total & $-.27^{* *}$ & $-.33^{* *}$ & $-.21^{* *}$ & $-.31^{* *}$ & $-.26^{* *}$ \\
\hline
\end{tabular}

PGWBI

Absence of Anxiety

$.15 \quad .19^{*}$

.12

.11

$.18^{*}$

Absence of Depression

$.28^{* *}$

$.33^{* *}$

$.19^{*}$

$.26^{* *}$

$.21^{* *}$

Positive well-being

$.26^{* *}$

$.26^{* *}$

$.23^{* *}$

.13

$.20^{* *}$

Self-control

$.23^{* *}$

$.30^{* *}$

.17

$.23^{* *}$

$.24^{* *}$

General health

$.19^{*}$

$.23^{* *}$

.11

$.19^{*}$

$.18^{*}$

Vitality

$.26^{* *} \quad .22^{* *}$

.17

.10

.16 
Validity and Reliability of the Italian ICQ

Total

$.28^{* *}$

$.31^{* *}$

$.20^{* *}$

$.20^{* *}$

$.24^{* *}$

QCAE

Perspective taking

$.35^{* *}$

$.42^{* *}$

$.25^{* *}$

$.52^{* *}$

$.26^{* *}$

Online simulation

.15

$.18^{*}$

.13

$.45^{* *}$

$.43^{* *}$

Emotion contagion

$-.10$

$-.12$

.03

.01

.03

Proximal responsivity

.17

.15

$.18^{*}$

$.45^{* *}$

$.25^{* *}$

Peripheral responsivity

.03

.01

.12

$.19^{*}$

.03

Cognitive empathy

$.30^{* *}$

$.35^{* *}$

$.23^{* *}$

$.56^{* *}$

$.40^{* *}$

Affective empathy

.04

.01

.15

$.27^{* *}$

.13

Total

$.24^{* *}$

$.27^{* *}$

$.24^{* *}$

$.55^{* *}$

$.37^{* *}$

NEO-FFI = NEO Five-Factor Inventory (McCrae \& Costa, 2004); DERS = Difficulties in

Emotion Regulation Scale (Gratz \& Roemer, 2004); PGWBI = Psychological General Well

Being Index (Dupoy, 1977, 1984); QCAE = Questionnaire of Cognitive and Affective Empathy

(Reniers et al., 2011); * $<.05$ after Bonferroni correction (i.e., uncorrected $p<.00037$ ); ** $p<$

.01 (i.e., uncorrected $p<.000074)$. 
Figure 1. Factor Structure of the Italian ICQ.

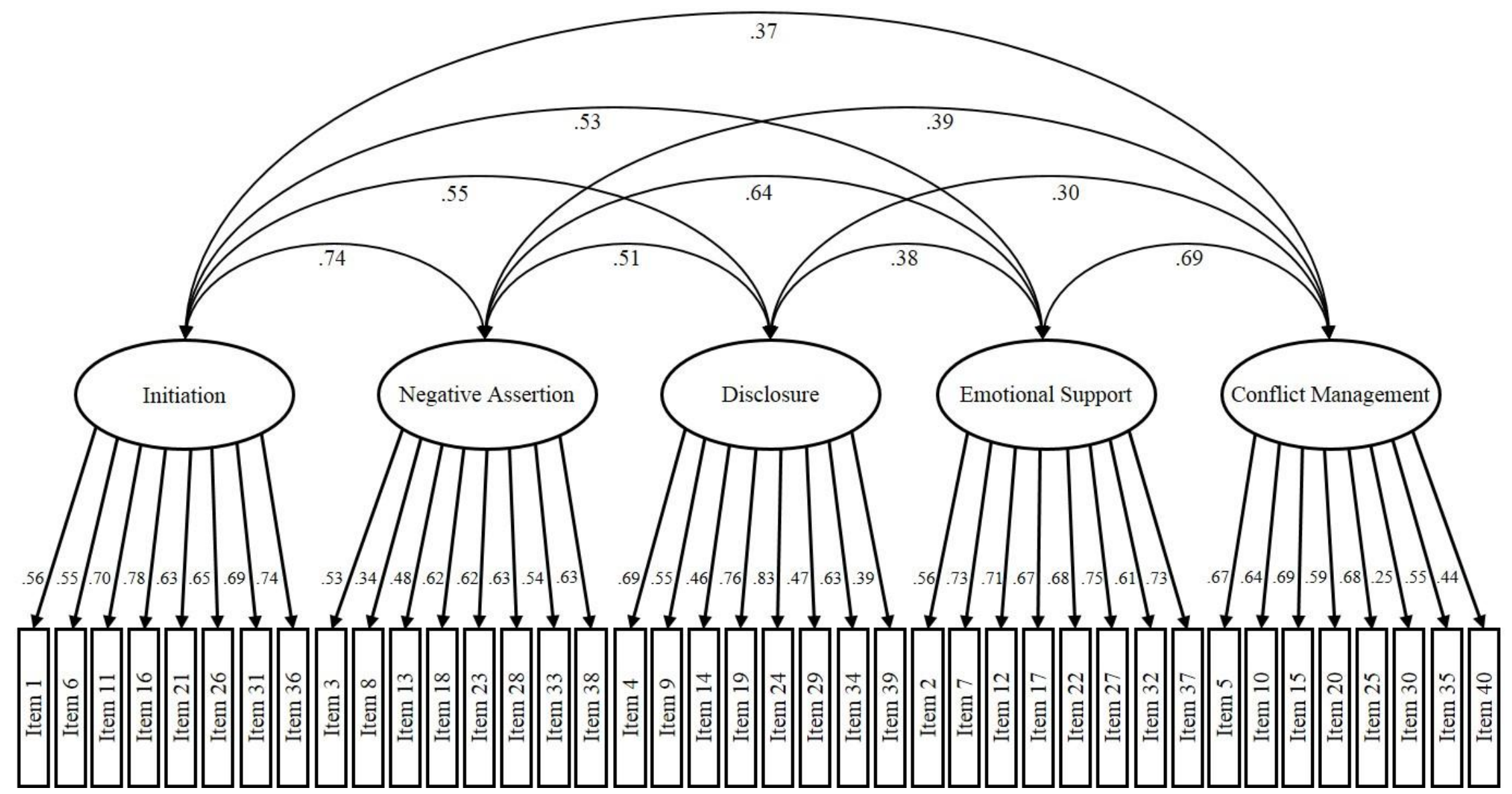

Note. For ease of presentation, error terms for items are omitted. Chi-Square $=1946.64 ;$ Degrees of Freedom $=730 ;$ Root Mean

Square Error of Approximation $($ RMSEA $)=.065 ;$ Comparative Fit Index $(C F I)=.95 ;$ Non-Normed Fit Index $(N N F I)=.94$. 